\title{
Effect of asymmetric elliptical shapes of the sealing ring sliding surface on the main parameters of the oil film
}

\begin{abstract}
This article discusses the results of simulation studies of the effect of selected sealing ring sets with asymmetrical elliptical sliding surfaces on the oil layer thickness distribution over the whole operating range of an internal combustion engine. The problem of calculating the sliding surface coverage with visco-elastic oil film as well as in mixed friction conditions is discussed. The effect of asymmetrical elliptical sliding surfaces particularly on the dimensionless slip and squeeze indicators was determined, defining these surfaces ability to produce an oil film.

The research results presented in this article show that there exists a real possibility of friction loss re-duction in the cylinder and sealing rings contact area, while maintaining the oil film continuity between the sliding surfaces.
\end{abstract}

Key words: rings with asymmetrical sliding surface shape, friction loss, oil film, quantification of lubricant oil consumption

\section{Introduction}

During piston engine operation, the lubrication conditions of the piston and the rings mounted on it are constantly changing. Variable gas and mass forces acting on the piston rings along with the changing temperature affect the oil film performance. By performing simulation studies on the oil film thickness distribution for a given engine design, areas on the cylinder surface where the oil film may break can be identified. This results in the fluid friction to change into mixed friction, or even into boundary friction under extreme conditions.

The ring sliding surface oil film thickness affects the pressure distribution in the oil film. The sealing rings sliding surface shape becomes a key factor in this case. A significant factor affecting the oil film instantaneous pressure distribution is the shape of this piston rings sliding surface obtained on the individual sections of the total axial surface height. The greatest challenge is determining the top sealing ring sliding surface shape, so that it both ensures the oil film continuity and at the same time reduces friction losses. Significant reduction of friction losses in the internal combustion engine can be achieved by selection of the sliding surface shapes of both the top and bottom sealing rings. In addition, the theoretical predictions regarding the piston rings sliding surface oil coating impede the conditions associated with the instantaneous parameters of lubrication oil and the instantaneous temperature distribution on the surfaces of the kinematic pairs. It is very difficult to obtain the planned oil film thickness distribution by shaping the geometry of the piston rings sliding surfaces and shaping the ring operation parameters, due to the complex relationship between them. The minimum oil film thickness between the sliding surface of the piston rings and the cylinder wall depends on the shape of the sliding surface directly covered by the oil film and on the thickness of the oil layer on the cylinder wall surface before and after the ring passes it. The oil film distribution and the resulting friction type, in addition to the conditions mentioned above, will also be influenced by other factors related to the type of lubricating oil used as well as its viscosity and temperature characteristics, the instantaneous position of the sealing ring sliding surfac- es within the piston groove and the oil film layers surface conditions.

Shaping the sliding surface of the piston rings directly affects the results of squeeze and slip, i.e., the instantaneous oil layer thickness left on the smooth surface of the cylinder wall after passage of the ring. The oil thickness in this area shapes the oil flow at the inlet to the next ring or to the same ring when returning through the cylinder. Depending on the shape of the sliding surface sections of this ring, the ring moves along the regions of various oil layer thickness at the piston's turning points. It can be stated, therefore, that a significant reduction in friction loss can be achieved primarily by setting the limit value of the minimum oil film thickness to be found on the cylinder wall after the ring passes, and the oil layer it leaves after its return just after the TDC. The thickness of the oil layer left behind by the top sealing ring at the piston's return point applies to a very short surface distance of the cylinder. The length of this section depends on the piston stroke and on the axial height of the upper ring. When analyzing these phenomena, it is also necessary to consider the forces from the gas acting on the upper sealing ring on this section of the piston path in the BDC direction, as well as the cylinder wall distance oilcoated by the bottom sealing ring moving towards the TDC in the previous stroke. The influence of these parameters must be taken into account when verifying the effect of the change in the sliding surface shape of the two sealing rings. Otherwise, the influence of these surfaces shape on the parameters defining the oil extrusion and lubrication effects may be misinterpreted.

Assuming that the sliding surface of the piston ring is not covered with the oil over its entire height, this area should be limited to just the section covered with the oil film. This requires describing complex surface shapes using appropriate mathematical functions or coefficients that define the approximate shape of the sliding surfaces. The asymmetric shape's effect of the piston rings sliding surface on their oil film coverage depends on the flow balance. In order to accurately analyze the effect of the sliding surface shape changes on the oily film distribution on its surface, the flow balance resulting from velocity areas should take into account. 
The shape of the piston rings sliding surface should be chosen in a way that ensures an oil film coverage continuity of these surfaces throughout the whole engine cycle. On the sliding surface of the top sealing ring, the continuity of the oil film should be maintained especially in the angle range of 345 to $390^{\circ}$ at the crankshaft. When analyzing such a crankshaft rotation angle range for the upper sealing ring, it is necessary to determine the path length just after TDC, on which the sliding surface of that ring moves on the oil layer left by its movement in the previous stroke. The distance to the end of this section, after which the sliding surface will encounter the oil layer left by the lower sealing ring before the piston's turning point also needs to be determined.

In the case of the most commonly used three ring piston design, in the suction and expansion strokes, the scraper ring moves over the oil layer accumulated on the cylinder wall and the remaining rings move over the layer left behind by the scraper ring. In the compression and exhaust strokes, the order of rings movement on the oil layer is reversed. The upper sealing ring moves only over the oil layer left by itself in the previous stroke, whereas the following rings move over the oil layer left by the preceding rings. In order to separate the sliding surfaces of the rings and the cylinder walls, a pressure must be created in the oil film that will determine its bearing capacity. In the expansion, exhaust and to some extent in the compression stroke, according to the pressure increase characteristic in the combustion chamber, the internal pressure in the oil film is influenced by the pressure of the gases acting on the inner surface of the piston ring. Depending on the adhesion of the ring sliding surface to the piston grooves surface resulting from the movement direction of the piston, it is the pressure from the space above or below the piston. In the intake stroke and to some extent the compression stroke the oil film pressure is affected by the ring's own elasticity and the distribution of specific pressures on the cylinder walls. The force exerted by the piston ring on the cylinder wall depends primarily on its geometrical dimensions, the type of material used, and the actual sliding surface covered by the oil film.

\section{The problem of calculating the sliding surfaces oil coverage for an oil film with partially elastic properties}

The effects of the temperature distribution, the lubricating oil dynamic viscosity, the specific pressure of the piston rings on the cylinder walls, the arrangement of all rings in the piston grooves and their geometrical dimensions on the piston rings sliding surface oil film thickness distribution are all well known. However, the currently produced synthetic oils are not perfectly viscous liquids and they do not show the elasticity that is manifested in compressibility. The partial elasticity of the oil results in different tangential pressures that affect the instantaneous friction forces occurring between the rings sliding surface and the cylinder walls [2]. In synthetic oils with elastic properties, there are other phenomena accompanying the distribution of the internal friction forces in the oil film, than in the mineral and semisynthetic oils. The adoption of these features into the simulation model for the analysis of the influence of the sealing rings sliding surfaces shape on the oil film surface is very important, as the reciprocal stresses due to viscosity and elasticity that occur in the turning points of the piston movement tend to combine.

According to the oil layer swelling theory, known as the Weissenberg effect, these oils can increase the oil coverage of the sealing rings sliding surfaces [4]. Accurately determining the effects of this phenomenon requires detailed experimental research, including the aspects of covering these surfaces at the piston's turning point. In this respect, the effect of the sliding surface shape of the upper sealing ring plays a crucial role in shaping the thickness of the oil film related to its return stroke and scraping the oil into the combustion chamber in the compression and exhaust stroke. Taking into account the resilient properties of semisynthetic and synthetic oils, the results can be expected to reduce the average friction losses in the oil film with a slight increase in losses at the piston turning points. Taking into account the resilient properties of these oils and evaluating their effect on the instantaneous oil film coverage of the upper sealing ring at the piston's turning points, an accurate mathematical model can be created to approximate the results that can define the effect of surface shape changes on the actual oil film coverage. Separation of the effects of these oils while simultaneously changing the shape of the sealing rings sliding surface requires experimental research.

In theoretical considerations this is not possible due to the error resulting from the introduction of the oil elastic modulus value into the mathematical model. Such a mathematical model would certainly make it possible to accurately predict the effects of changes in the rings sliding surfaces shape in terms of engine friction losses reduction while maintaining the durability of its kinematic connection of the main mechanisms and the engine timing. Another difficulty is creating a reliable mathematical description of the actual oil film volume at the piston's turning points, even if the oil is assumed to be only a viscous fluid.

Taking into account the theoretical considerations of the oil partially elastic one should also take into account the conditions when mixed friction occurs. For this purpose, an anisotropic friction model can be used, in which the value of the friction coefficient is calculated based on the slipping direction of the surface microroughness. At the moment the sealing rings sliding surfaces move on the cylinder walls, the main friction directions are perpendicular to each other. Such calculations use an elastic-plastic friction model.

These phenomena are broadly illustrated in the works of Maksak [12], which investigated the effect of tangential direction on the preliminary displacement values for metal surfaces, including spheroidal cast irons used for the production of piston rings. Based on the results of the Maksak study, it can be assumed that friction coefficient values decrease for samples with machining indications directed along the sliding direction, and increased - if the machining marks are perpendicular. In addition, displacement in the elastic range occurs only for a specific static load [15-17]. Thus increasing the static load resulting from the instantaneous changes in the piston movement direction will result in a macro-slip, preceded by the appearance of reciprocal elastic-plastic displacements in certain areas of the rings sliding surface and the cylinder walls. Displacement in the 
elastic range is referred to as micro-slip and in these considerations concerns only the instantaneous friction between the rings and the cylinder walls. An unloading and reloading of the sealing rings sliding surfaces pressure will result in a permanent plastic displacement as a difference of total displacement and the elastic preliminary displacement.

According to Fredriksson's experimental research, reducing the roughness of the metal surfaces results in an increase in the friction coefficient in spite of the contact pressure being the same.

Considering the conditions described above, it is possible to determine the change in friction coefficients of spheroidal cast irons covered with selected piston ring protective coatings, depending on the method of shaping the asymmetrical sliding surfaces of the piston rings under instantaneous friction conditions. Adoption of the aforementioned conditions guarantees a precise theoretical definition of the effect of piston rings sliding surfaces shape change for fixed engine material and geometric requirements for the conditions where these surfaces are separated with visco-elastic oil film, as well as in mixed friction conditions. In addition, the mathematical modeling of the phenomena occurring at the piston rings sliding surfaces in mechanical friction conditions can be used to precisely predict the change in shape of these surfaces during the break-in period. Because every geometric change of the sealing rings asymmetrical shape affects the oil film thickness distribution on the cylinder wall surface over the entire engine life.

Currently, the most accurate available method for determining the impact of all the discussed conditions is exclusively experimental research of the piston ring operation with cylinder walls under certain engine operating conditions. It is worth mentioning that the measurements of piston rings sliding surfaces, piston and cylinder walls are the most important for guaranteeing the reliability of the obtained friction loss and oil film thickness results before, during, and after the completion of the tests.

\section{Partial filling of the space beneath the asymmet- ric sliding surface with oil}

Simulation studies on the asymmetric change in the piston rings sliding surfaces shape require the inclusion of many variables that are difficult to determine. However, irrespective of the shape of these surfaces, their oil film coverage area results from the flow balance. As mentioned previously, this balance also depends on the type of liquid used to separate the sliding surfaces.

In the assumed mathematical model [3] the oil exhibits viscosity but has no elastic properties. Taking into account such criteria at this stage of the study provides sufficient accuracy to determine the effect of the changes in the sliding surfaces shape on their oil film coverage. In all simulations, the asymmetrical shape of the sliding surface of both sealing rings is assumed in various combinations in the piston grooves. Based on the flow balance, it can be shown that the distribution of the oil film pressure affects not only the thickness of these film surfaces but also affects the position of the center and the angle values defining the selected parabolic shapes.
The sliding surfaces asymmetric spherical shapes with parabola peaks between 5 to 20 microns relative to the side edges of the rings and their different arrangements at axial ring heights were selected for the study. Based on experimental measurements of the actual piston rings shape, the selected asymmetrical spherical shapes are preserved for most of the samples over the entire circumference of the ring with a tolerance of about 1 micron. Such accuracy enables a real assessment of the effect of these surfaces shape change on friction losses and oil film parameters. On the other hand, repeatedly producing these surfaces in the ring cross-section at the technological stage is very difficult, since the asymmetric barrel shape error, i.e. the center of the parabola tip, and the height of the parabola with respect to the ring side edges, are in average between 3 and 5 microns. However, this is not a problem when selecting identical sliding surfaces for large production cycles for experimental purposes. The sliding surface shape of these rings around their circumference may be determined by means of profilers or visual-measuring devices.

The mathematical expression of asymmetric shapes similar to elliptic figures forces the assumption of certain distance values between the antipodal points of the ellipse, where the center of the line defined by these points, is the ellipse's center of symmetry relative to the transverse diameter and the conjugate diameter. Adopting elliptic shapes allow to determine the ellipse position center and the antipodal points distance that express the transverse diameter and the conjugate diameter values. In the case of asymmetrical shapes described using parabolic combinations, the comparison of friction losses and oil film parameters can be expressed based on the parabolic center position with its angle in that point defining the distance of the rings sliding surfaces from the cylinder surface. Manipulation of ellipsoidal angles and coordinates of their position and parabolic angles at the level of several micrometers of the ring cross section greatly influences the distribution of the velocity fields components at the starting and separating points of the oil film.

With the mathematical model used it is possible to analyze the phenomena accompanying the partial oil filling of the space under the piston rings sliding surface as well as the space between them by mapping the surface with straight line sections. As a result, a model simulating parabolic and sinusoidal surfaces using a specified number of broken curves was created. To make comparing the effects of implementing asymmetric parabolic or elliptical shapes possible, the values of the dimensionless slip and extrusion effects coefficients for these cross sections should be established. In the simulated type of reciprocating internal combustion engine, the manufacturer used a nose shape for the lower sealing ring and a symmetrical barrel shape for the upper sealing ring.

The dimensionless slippage and extrusion effects coefficients determine the rings sliding surface ability to form an oil film. It has been established so far that the highest values of slip rates have been obtained for stepped and twostep surfaces. On the other hand, the values of the extrusion coefficients increase as the interacting surfaces approach the parallel level. It is therefore justified to create a coeffi- 
cient that would allow the sliding surface shape contours to be compared in terms of slip and extrusion coefficients. Due to the fact that the parallel position of the opposing surfaces may be unpredictable and vary during the entire engine life, it is important to adjust the sliding surface contours so that the values of the slip and extrusion effects are as large as possible within the limits set by the construction goals. The asymmetric contours arrangement defining the sealing rings sliding surfaces shape results in more favorable results than symmetric contours arrangement or the formation of circumferential grooves on these surfaces [16].

The upper sealing ring sliding surface contours should promote an asymmetrical shape with high slip coefficient values and low values of the extrusion coefficient. Contours characterized by a high value of slip coefficient should be located on the sliding surfaces on the crankcase side in the case of piston movement towards the TDC in the compression and exhaust strokes. Contours with small values of extrusion coefficient must be introduced in the opposite manner. Such a sliding surface design favors leaving an increased oil film thickness after the ring passage just before the piston's turning point. This provides reasonable conditions for liquid friction to occur along the return path of this ring before its sliding surface shape meets the oil layer left by the lower sealing ring. In this case, the contours with low extrusion coefficient values introduced on the sliding surface from the combustion chamber's side reduce the thickness of the oily film left behind by the ring in the intake and expansion strokes. This is acceptable since the upper sealing ring in the subsequent compression and exhaust strokes no longer generate as large gas forces as the expansion stroke. The reduced value of the gas force within this angle range on the crankshaft promotes the automatic increase of the oil film thickness by decreasing the specific pressure. Due to the fact that the load acting on the upper ring is smaller than at the piston's turning points just after the TDC, it is acceptable for the upper sealing ring to leave a thinner oil film within this crankshaft angle range. This improves the lubrication conditions of the upper sealing ring at the more heavily loaded crankshaft angles, resulting in the asymmetric position of the apex, i.e. the critical contour center at the axial ring height.

The contours of the lower sealing ring sliding surface should be able to achieve a high extrusion coefficient value and a low slip coefficient value. Contours with high extrusion coefficient values must be located on the sliding surface from the combustion chamber side, and the contours of the low slip coefficient values on the opposite side. This is caused by the shift of the critical contour center tip to the ring sliding surface part from the combustion chamber side. Such contour placement defines the shape of a sliding surface that favors oil scraping on the upper sealing ring slide surface during the compression and exhaust stroke due to the high value of the extrusion coefficient on that side of the ring. This sliding surface shape of the lower sealing ring reduces the oil film thickness left during its movement in the TDC direction. As a result, the lower ring moves over a reduced oil film thickness in the expansion stroke, where the load absorbed by the ring grows. This is very advantageous because the thickness of the oil layer left by the scraper ring is sufficient to ensure the continuity of the oil film and, in addition, the reduced oil thickness for this ring results in a reduction in friction loss in this crankshaft angle range.

These observations indicate the positive effects of modifying the contours defining the sliding surface shape for both rings and its effect on the slip and extrusion coefficient values. As noted, the position of these contours corresponding to the values of the slip and extrusion coefficients is different for each sealing ring, and should be selected based on the load transmitted by the respective ring in a given crankshaft angle region of the engine operating cycle.

The results of previous simulations did not clearly show the effect of sliding surfaces asymmetric contours angles on the values of slip and extrusion coefficients. An important parameter determining the value of these indicators beyond the contour angle is also the position of the critical contour center tip, where there is a change in the sectional effects of slip and extrusion. The offset of the critical contour center to the outer edge of the sliding surface profile directly affects the contour angle, and thus, it increases to the extrusion coefficient value.

Based on the previous model [2], approximative extrusion and slip effects coefficients can be determined for the entire sliding surface of a given ring. However, a thorough analysis of the phenomena occurring on surfaces with a parabolic curvature, and not solely rectilinear, requires the addition of additional approximation coefficients or an increase in the number of calculation steps of the current mathematical model, which will be the subject of subsequent studies.

Because of the complex relationship of the ring position with parameters characterizing the design of the engine components, its operating conditions and the properties of the oils, determining the coefficients approximating the phenomena resulting from the effects of slip and extrusion is preferred. Based on the assessment of these phenomena and the assumed changes in the ring's direction within the piston groove, tilt effect coefficients can be determined and linked to the slip and extrusion effects. The position of the ring is in particular influenced by the hydrodynamic pressure in the oil film and by the ring's own elasticity. To approximate the most important aspects of effective shaping of the upper sealing ring sliding surface by changing the value of the extrusion and slip coefficients, it is necessary to first determine the area of operation in which the mixed friction phenomenon can occur. The distance traveled by the upper sealing ring until it encounters the oil film left by the lower sealing ring during the return movement can be described by the equation:

$$
\mathrm{a}_{\mathrm{cpg}}=\mathrm{a}_{\mathrm{g}-\mathrm{d}} \pm \mathrm{a}_{\mathrm{vg}} \pm \mathrm{a}_{\mathrm{vd}}
$$

The length of this path described in crankshaft degrees can be expressed by:

$$
\mathrm{a}_{\mathrm{OWK}}=\frac{180}{\mathrm{~S}} \times \mathrm{a}_{\mathrm{cpg}}
$$

where: $a_{c p g}$ - distance from the oil film start point on the sliding surface profile of the upper sealing ring to the oil film separation on the sliding profile surface of the lower 
sealing ring, $\mathrm{a}_{\mathrm{g}-\mathrm{d}}$ - distance from the axial center of the upper sealing ring to the middle center of the lower sealing ring, $a_{v g}$ - distance from the axial center of the upper sealing ring height to the oil film layer edge on the sliding profile surface, $a_{v d}$ - distance from the axial center of the lower sealing ring height to the oil film separation on the sliding profile surface, $\mathrm{a}_{\mathrm{OWK}}$ - the distance expressed in crankshaft rotation degrees, $\mathrm{S}-$ piston stroke.

For a $70 \mathrm{~mm}$ piston stroke internal combustion engine, this path averages out between 10 to $13^{\circ}$ on the crankshaft just after TDC, depending on the shape of the sliding surface of the two sealing rings, their axial height and their respective positions in the piston. The shape of the top sealing ring sliding surface should allow for the thickest possible layer of the oil film behind the ring leading to the TDC on the path section covered by its return movement. This shape also needs to allow as little oil consumption as possible while reducing friction losses with respect to the reference ring sliding surface shape.

\section{Analysis of oil film parameters and friction loss- es for selected sets of piston rings with asymmetric sliding surfaces}

In the simulation studies, the asymmetric spherical shape of the lower and upper sealing rings was assumed. Simulation studies on oil film thickness and friction losses were made for the characteristic axes in the plane of the piston pins motion. The following sets of piston rings placement in the piston groove have been used:

- reference ring set - upper and lower sealing ring - reference shapes for the given engine,

- ring set 1 - upper sealing ring - parabolic peak located in the crankcase side sliding surface and lower sealing ring - parabolic peak on the side of the combustion chamber - optimal ring set,

- ring set 2 - upper and lower sealing ring - parabolic peak located in the sliding surface on the crankcase side,

- ring set 3 - upper and lower sealing ring - parabolic peak located in the sliding surface on the combustion chamber side.

From the analysis of Figure 1, it is clear that the good oil film characteristics while reducing friction losses are obtained for the asymmetric spherical surfaces of the lower sealing ring with the center of the parabolic peak located in the sliding surface on the combustion chamber side - ring sets 1 and 2. Such a sliding surface shape of the lower sealing ring allows for the formation of a greater oil film thickness than in the reference shape and an oil film on the turning point of the upper sealing ring at about $15^{\circ}$ on the crankshaft after the TDC, representing the expansion stroke, and a lower oil film thickness retained for the return movement of that ring in the BDC direction. Reducing the oil film thickness on the lower sealing ring sliding surface in the range of 20 to $180^{\circ}$ on the crankshaft without the risk of mixed friction is very useful. It reduces the friction loss of this ring towards the BDC in the expansion stroke, while maintaining the conditions necessary to produce fluid friction throughout the entire crankshaft angle and at the maximum permissible load for the engine. The reverse situation occurs for the upper sealing ring. For this ring, the parabol- ic peak defining the asymmetric shape should be located on the crankcase side. Such a sliding surface shape of the upper ring provides less scraping of the oil to the combustion chamber in the compression and exhaust strokes, reducing friction losses and ensuring increased oil film thickness and retaining the film in the crankshaft angle of 0 to $15^{\circ}$ after the TDC in the expansion stroke.
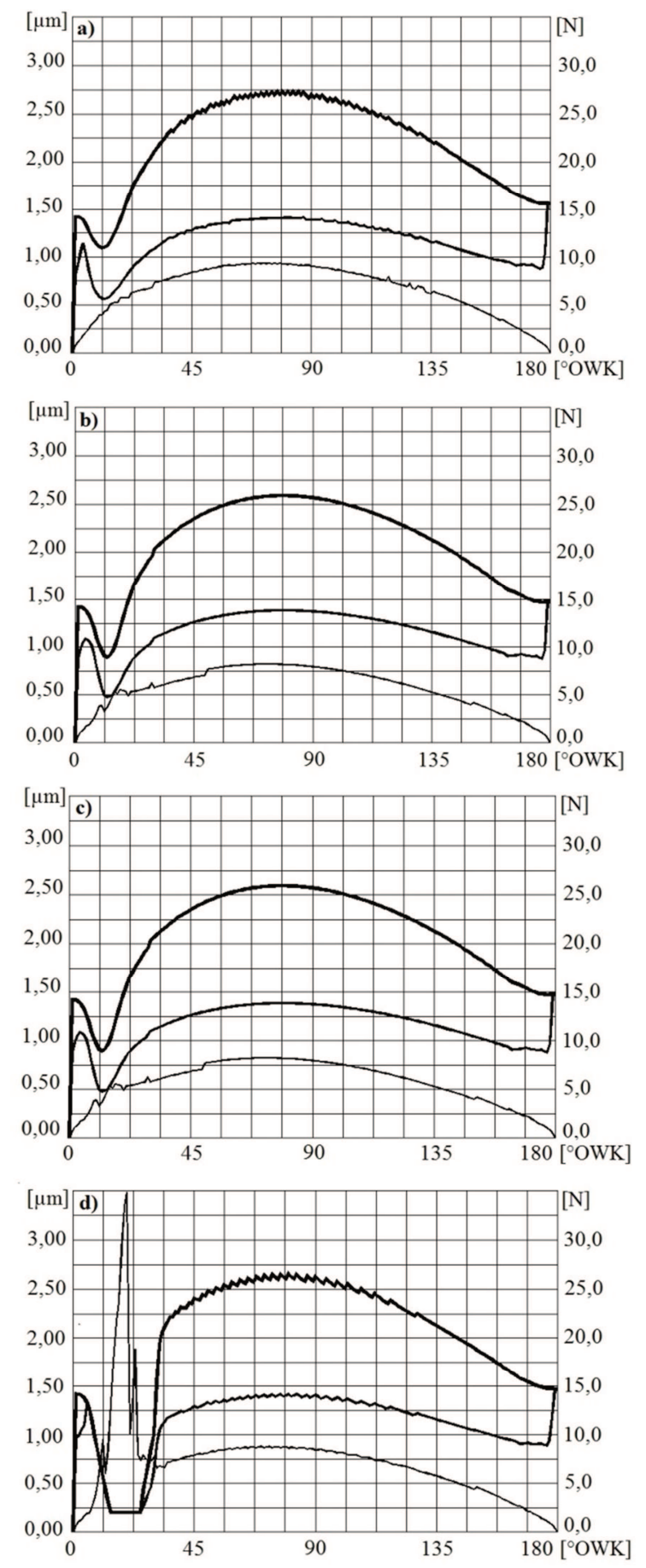

Fig. 1. The change in the oil film thickness, friction and the thickness of the oil layer left on the cylinder wall by the lower sealing ring after completing the TDC-BDC stroke; thick line - film, medium line - layer, thin line - friction, a) reference ring set, b) ring set 1 , c) ring set 2 , d) ring set 3

As shown in Figure 1, the insertion of the lower sealing ring with an asymmetrical sliding surface with the parabolic 
peak on the side of the combustion chamber (ring sets 2 and 3) ensures oil film continuity just after the TDC in the expansion stroke. Within this angle on the crankshaft, the lower sealing ring has the highest gas force value, which can lead to breaking the oil film continuity. The analysis of Figures 1 and 2 leads to the statement that the oil layer distribution on the lower ring sliding surface for ring set 1 and 2 is similar to the reference distribution while simultaneously reducing the friction force in the return stroke of the ring.

Such a distribution of the oil film indicates a greater scraping of the oil by the lower sealing ring under the upper ring and leaving the reduced film thickness for the return movement of the piston. This sliding surface shape of the lower ring, in spite of the reduced oil film thickness, ensures continuity of its sliding surface coverage throughout the engine work cycle, especially just after TDC in the expansion stroke. Introducing the shape of ring set 3 for the lower sealing ring is not recommended. With this sliding surface shape, the oil film is broken off immediately after the piston's turning point, which promotes mixed friction and, in extreme cases, boundary friction. For this shape of the lower ring in the range of 5 to $34^{\circ}$ on the crankshaft after the TDC in the expansion stroke, a sharp reduction in oil film thickness can be observed. This is due to the simulation program limitations and the reduction of these values to less than $0.200 \mu \mathrm{m}$. However, it is expected that such a slight surface roughness is impossible to obtain at the manufacturing stage and will probably result in mixed friction. Such a distribution of the oil film in this range of crankshaft angle is very unfavorable, because it affects the intensification of the operational wear of the lower sealing ring and cylinder wall sliding surfaces.

In addition, the lower ring sliding surface shape presented in ring set 3 increases the friction power of this ring by $1 \mathrm{~W}$ relative to the reference ring set and $4 \mathrm{~W}$ in relation to ring sets 1 and 2 at $3000 \mathrm{rpm}$. Increased friction losses for these ring sets result from breaking of the oil film continuity in the initial range of the crankshaft angle just after the TDC in the expansion stroke. From data in Table 1, it is clear that for ring set 1 the greatest reduction in friction losses is observed with respect to the reference set, while maintaining the favorable conditions for covering the sliding surfaces of the lower and upper sealing rings. For ring sets 1 and 2, the lower friction of the lower sealing ring $\mathrm{N}_{2}$ is identical - it is equal to $20 \%, 11.11 \%$, and $13.85 \%$ for engine speeds of $1000 \mathrm{rpm}, 3000 \mathrm{rpm}$ and $5000 \mathrm{rpm}$ respectively.
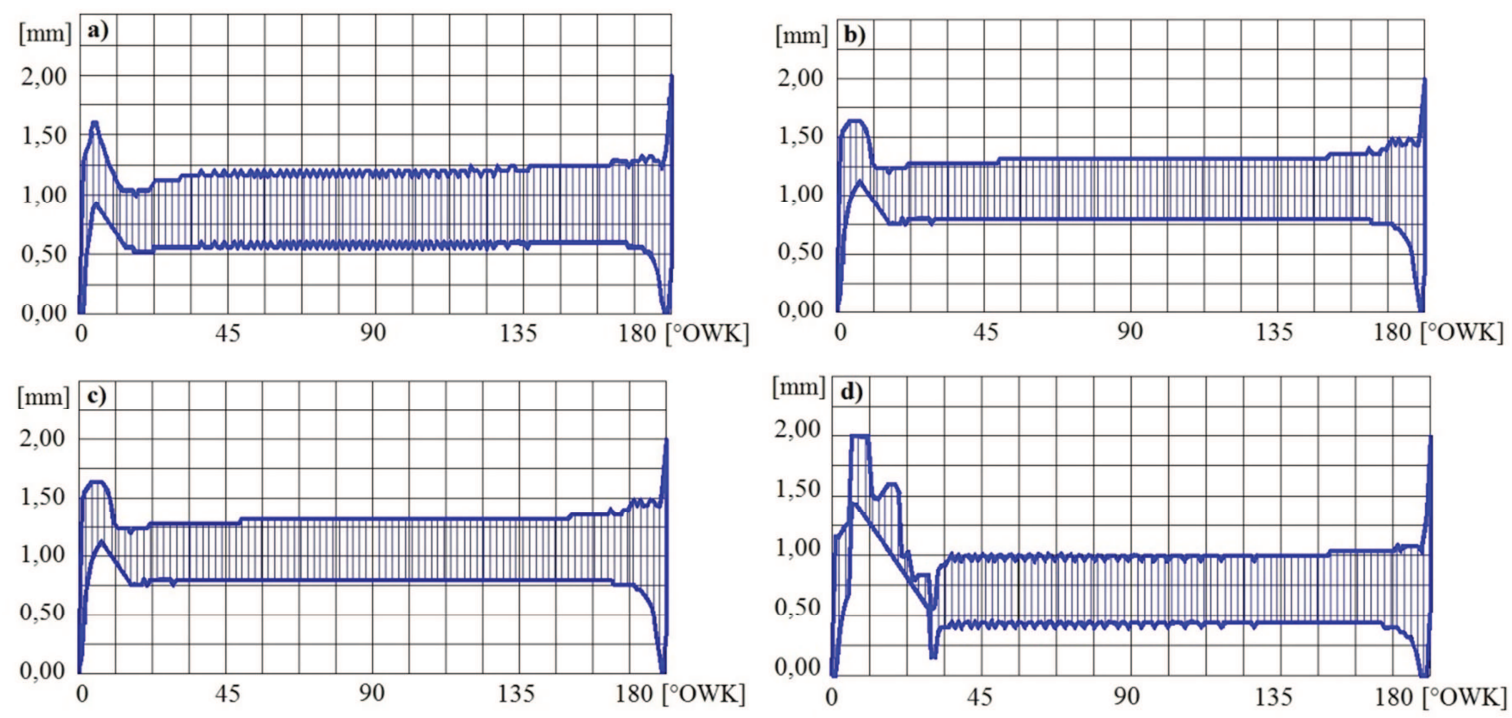

Fig. 2. Lower sealing ring sliding surface oil film layer after the TDC-BDC stroke; a) reference ring set, b) ring set 1 , c) ring set 2 , d) ring set 3

Table 1. Values of power and friction force for selected piston ring sets

\begin{tabular}{|c|c|c|c|c|c|c|}
\hline $\begin{array}{l}\text { Piston ring } \\
\text { setup } \\
\text { variant }\end{array}$ & $\begin{array}{l}\text { Engine } \\
\text { speed } n \\
{[\mathrm{rpm}]}\end{array}$ & $\begin{array}{l}\text { Friction power of } \\
\text { the upper sealing } \\
\text { ring } N_{1}[\mathrm{~W}]\end{array}$ & $\begin{array}{c}\text { Friction power } \\
\text { of the lower } \\
\text { sealing ring } \mathrm{N}_{2} \\
\text { [W] }\end{array}$ & $\begin{array}{l}\text { Friction power of } \\
\text { the scraper ring } \\
\mathrm{N}_{3}[\mathrm{~W}]\end{array}$ & $\begin{array}{l}\text { Friction power of } \\
\text { a piston ring set } \\
\mathrm{N}_{\text {rsum }}[\mathrm{W}]\end{array}$ & $\begin{array}{l}\text { Friction force at } 20^{\circ} \text { on the } \\
\text { crankshaft after the TDC for } \\
\text { the upper sealing ring }[\mathrm{N}]\end{array}$ \\
\hline \multirow{3}{*}{$\begin{array}{l}\text { Reference } \\
\text { ring set }\end{array}$} & 1000 & 10 & 5 & 6 & 27 & 4.3 \\
\hline & 3000 & 60 & 27 & 36 & 159 & 8.4 \\
\hline & 5000 & 142 & 65 & 83 & 374 & 11.1 \\
\hline \multirow[t]{3}{*}{ Ring set 1} & 1000 & 7 & 4 & 6 & 23 & 3.6 \\
\hline & 3000 & 45 & 24 & 36 & 141 & 6.7 \\
\hline & 5000 & 105 & 56 & 83 & 327 & 8.9 \\
\hline \multirow[t]{3}{*}{ Ring set 2} & 1000 & 8 & 4 & 6 & 24 & 3.9 \\
\hline & 3000 & 47 & 24 & 36 & 143 & 7.3 \\
\hline & 5000 & 108 & 56 & 83 & 330 & 9.9 \\
\hline \multirow[t]{3}{*}{ Ring set 3} & 1000 & 7 & 4 & 6 & 24 & 3.6 \\
\hline & 3000 & 46 & 28 & 36 & 146 & 6.6 \\
\hline & 5000 & 108 & 65 & 83 & 339 & 8.8 \\
\hline
\end{tabular}


Figure 3 indicates that the asymmetric shape of the lower sealing ring for ring sets 1 and 2 reduces the oil film thickness of that ring to below the thickness of the oil film of the scraping ring. For the reference ring a slight increase in oil film thickness is observed to above the film thickness value of the scraper ring. Such situation leads to the reduction of the friction losses for both sealing rings while maintaining the oil film continuity in the most heavily loaded areas from 0 to $50^{\circ}$ on the crankshaft immediately after the TDC in the expansion stroke. By analyzing the graphs in Figures 1, 2 and 3 on the oil film distribution for the lower sealing ring, it can be stated that the use of asymmetrical shapes with the parabolic peak on the combustion chamber side makes it possible to significantly reduce friction losses while maintaining the oil film in all engine strokes. This means that this direction of piston ring sliding surface design enables high values of the extrusion coefficient and low values of the slip coefficient for these shapes. An important aspect of such modeling is the need to determine the whether the sealing rings retain their given shape after the adjustment of their sliding surface to the cylinder walls in engine break-in. In this case the decisive role in maintaining or slightly adjusting the sliding surface of the two sealing rings (at the level not exceeding 1-2 micrometers) plays the type of protective coating used on the sliding surfaces of the rings and the cylinder walls. The degree of changes in the original sealing ring sliding surface shape is affected by the thickness of the applied coating, friction wear resistance, sliding surface forming technology, surface roughness for all co-operating surfaces of the kinematic pairs, and the quality and viscosity of the applied lubricant.

The most favorable oil film distribution in the range of 332 to $390^{\circ}$ on the crankshaft is obtained for ring set 1 , as shown in Figures 4 and 5. In addition, the largest reduction in friction power for the upper sealing ring N1 was 30\%, 25\% and $26.06 \%$ for $1000 \mathrm{rpm}, 3000 \mathrm{rpm}$ and $5000 \mathrm{rpm}$ respectively, and for the whole piston rings set $\mathrm{N}_{\text {rsum }}$ : $14.81 \%$, $11.32 \%$ and $12.57 \%$ for $1000 \mathrm{rpm}, 3000 \mathrm{rpm}$ and $5000 \mathrm{rpm}$ respectively. Reduction of friction in $20^{\circ}$ on the crankshaft after TDC for upper sealing ring is $-16.28 \%, 20.24 \%$ and $19.82 \%$ for $1000 \mathrm{rpm}, 3000 \mathrm{rpm}$ and $5000 \mathrm{rpm}$ respectively.

In Figures 4 and 5 for ring set 1 , the continuity of the upper sealing ring sliding surface oil layer can be observed throughout the entire crankshaft angle range, particularly from 360 to $390^{\circ}$ on the crankshaft. For ring set 2, the upper sealing ring sliding surface is shifted away from the combustion chamber side in movement towards the TDC in the compression and exhaust stroke, which promotes the scraping of larger amounts of oil in this engine operating range and increases the consumption of the engine oil. Such a situation not only reduces the engine operation economy, but also damages the sliding surface interaction of this ring with the cylinder wall, as shown in Figures 4 and 5. For this
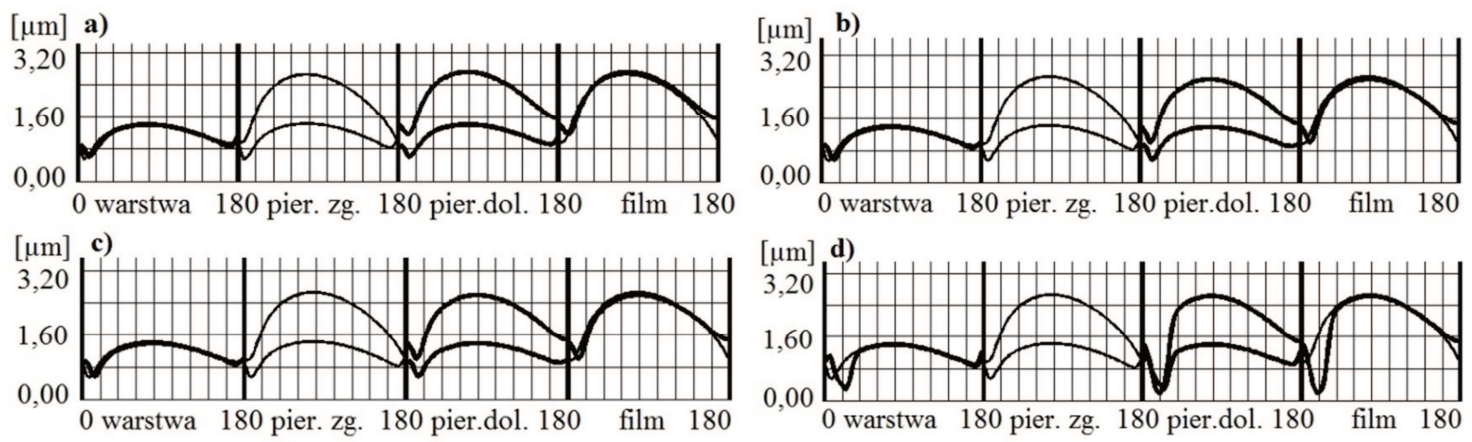

Fig. 3. The oil film layer distribution for the lower sealing ring and the scraper ring after the TDC-BDC stroke; a) reference ring set, b) ring set 1 , c) ring set 2 , d) ring set 3
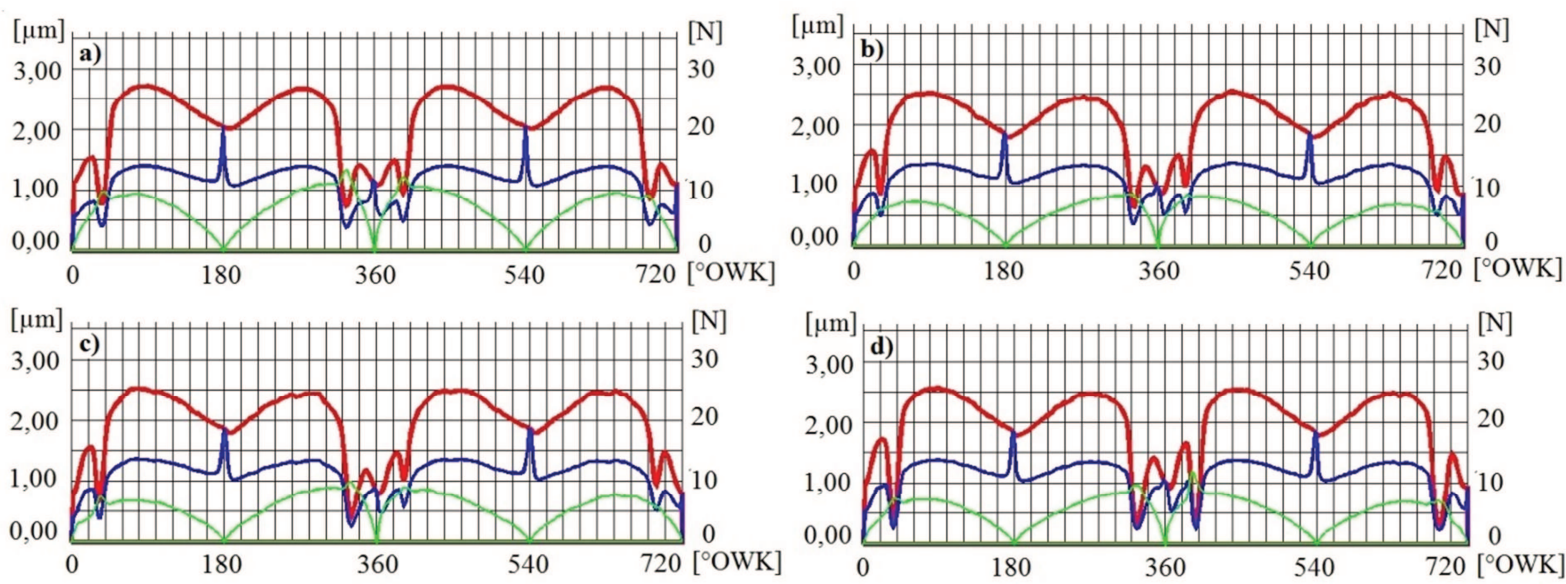

Fig. 4. Changing the upper sealing ring oil film coverage - blue line, oil film thickness - red line, friction forces - green line as a function of the crankshaft angle; a) reference ring set, b) ring set 1 , c) ring set 2 , d) ring set 3 

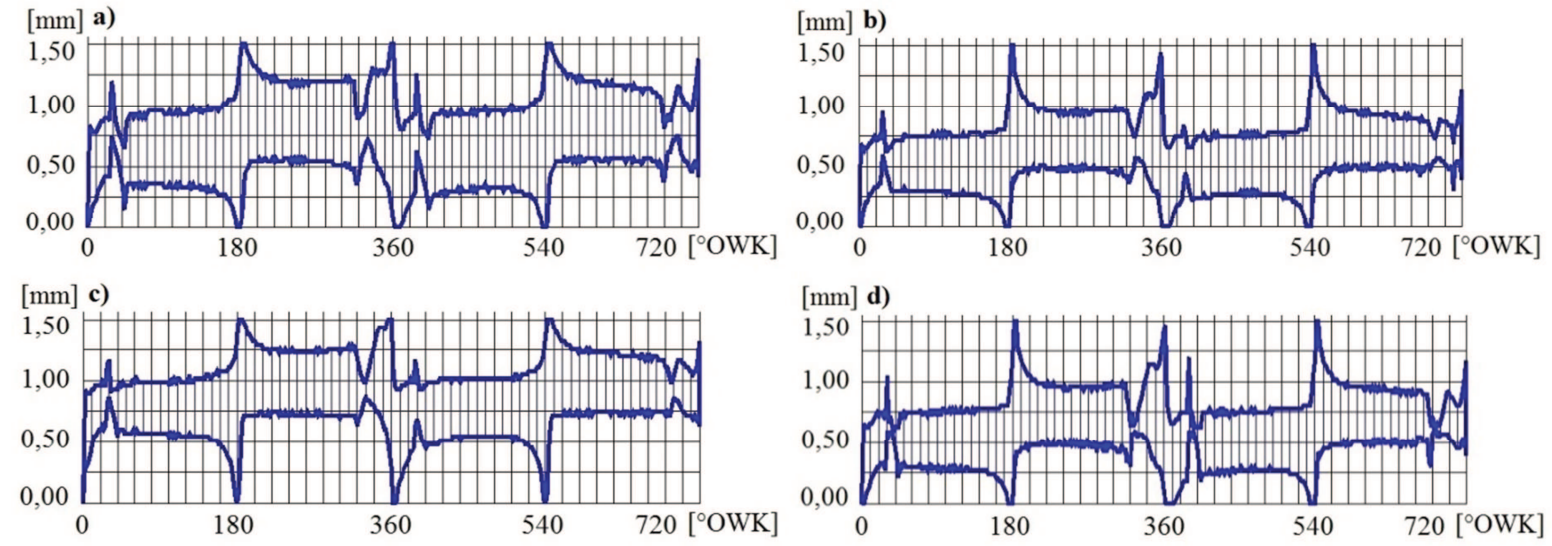

Fig. 5. Change in the upper seal ring sliding surface oil film coverage for characteristic axes in the plane of the piston pins motion; a) reference ring set, b) ring set $1, \mathrm{c}$ ) ring set $2, \mathrm{~d}$ ) ring set 3

combination, the thickness and width of the oil film coverage between 330 and $335^{\circ}$ on the crankshaft before TDC in the compression stroke is significantly reduced. It is particularly dangerous to reduce the oil film coverage of the top sealing ring sliding surface in the plane of its largest point of this surface, i.e. the peak of the parabola just before the TDC at $334^{\circ}$ on the crankshaft in the compression stroke and at $387^{\circ}$ on the crankshaft in the expansion stroke. In these areas, despite favorable engine operating conditions, there will certainly be a break in oil film continuity.

The areas of reduced oil film coverage and reduced oil layer thickness on the upper sealing ring sliding surface are varied and are not a reference point for a larger group of asymmetric piston rings. These areas depend on many individual piston-crank design factors and the actual engine operating conditions. However, the example of reducing the coating and the oil layer thickness for these ring sets indicates some tendencies for changes in these parameters that occur when shaping the geometry of the asymmetrical piston rings sliding surfaces.

From Figures 4 and 5 as well as Table 2, it can be seen that ring set 3 exhibits unacceptable variations in the thickness and coverage of the sliding surface oil film of these rings. A sharp reduction in oil film surface coverage is observed at $326^{\circ}$ on the crankshaft in the compression stroke and at $391^{\circ}$ on the crankshaft in the expansion stroke. A breach in the oil film continuity occurs at these points. Based on the data in table 2, it can be stated that there is no constant crankshaft angle value for different asymmetrical shapes and their combinations that would define the minimum oil film thickness. The value of this parameter, depending on the different asymmetrical shapes cooperation conditions and various operating conditions of the engine, is shifted closer or further from the TDC. This is shown in Figure 5 - by the blue line, where the minimum oil film thickness for ring sets 1,2 and 3 is different. For example, for ring set 1 , it is approximately $336^{\circ}$ on the crankshaft in the compression stroke and $389^{\circ}$ on the crankshaft in the expansion stroke, for Pack 2 at approximately $333^{\circ}$ on the crankshaft in the compression stroke and $391^{\circ}$ on the crankshaft in the expansion stroke, and for ring set 3 at approximately $326^{\circ}$ on the crankshaft in the compression stroke and $395^{\circ}$ on the crankshaft in the expansion stroke.
Table 2. Oil film thickness values at $5^{\circ}$ and $10^{\circ}$ on the crankshaft after the TDC in the expansion stroke for selected ring sets

\begin{tabular}{|l|c|c|c|}
\hline $\begin{array}{l}\text { Piston ring setup } \\
\text { variant }\end{array}$ & $\begin{array}{c}\text { Engine } \\
\text { speed } \mathrm{n} \\
{[\mathrm{rpm}]}\end{array}$ & $\begin{array}{c}\text { Oil film thick- } \\
\text { ness } 5^{\circ} \text { after } \\
\text { TDC }[\mu \mathrm{m}]\end{array}$ & $\begin{array}{c}\text { Oil film thick- } \\
\text { ness } 10^{\circ} \text { after } \\
\text { TDC }[\mu \mathrm{m}]\end{array}$ \\
\hline \multirow{2}{*}{$\begin{array}{l}\text { Reference piston } \\
\text { ring set }\end{array}$} & 1000 & 0.657 & 0.711 \\
\cline { 2 - 4 } & 3000 & 1.084 & 1.168 \\
\cline { 2 - 4 } & 5000 & 1.580 & 1.633 \\
\hline \multirow{3}{*}{ Ring set 2 } & $\mathbf{1 0 0 0}$ & $\mathbf{0 . 4 2 7}$ & $\mathbf{0 . 5 2 0}$ \\
\cline { 2 - 4 } & $\mathbf{3 0 0 0}$ & $\mathbf{0 . 8 8 0}$ & $\mathbf{1 . 0 1 7}$ \\
\cline { 2 - 4 } & $\mathbf{5 0 0 0}$ & $\mathbf{1 . 1 4 8}$ & $\mathbf{1 . 3 2 2}$ \\
\cline { 2 - 4 } & 1000 & 0.322 & 0.500 \\
\cline { 2 - 4 } & 3000 & 0.803 & 0.995 \\
\hline Ring set 3 & 5000 & 1.259 & 1.433 \\
\cline { 2 - 4 } & 1000 & 0.455 & 1.041 \\
\cline { 2 - 4 } & 3000 & 0.918 & 1.344 \\
\hline
\end{tabular}

It can therefore be considered that the lower the oil film thickness encountered by the upper sealing ring in the piston movement towards the TDC in the compression stroke and to the BDC in the expansion stroke, the larger the distance of the crankshaft angle between points defining the minimum oil film thickness. If the oil film thickness encountered in both directions is large enough, both points defining the minimum film thickness for the upper sealing ring slide surface are approaching the crankshaft angle near the TDC. This is a valuable observation that indicates that the susceptibility of the points of minimum oil film thickness in the compression and expansion strokes closely depends on the shape and the asymmetry of the opposing sliding surfaces of both the sealing rings. This dependence is also repeated for other geometric dimensions of pistoncrank assemblies, which justifies the practical application of this relationship to a wider group of engines.

It can also be noted that in considering the oil layer distribution on the two sealing rings sliding surfaces, in numerical methods significant parameters should not be linearized. The goal should be to precisely express the change of the gap between the kinematic pairs surfaces that limit the lubricant wedge. Linearization of the two opposing surfaces shape geometry may lead to a significant error resulting in misinterpretation of the change in this parameter and its effect on the oil film distribution on the piston rings sliding surface. Similar recommendations also apply 
to the speed of the wedge thickness change. In these cases increasing the parameters and auxiliary parameters accura$\mathrm{cy}$, that result from the hydrodynamic lubrication theory, greatly increases the complexity of the mathematical model used in the numerical calculations.

\section{Quantitative oil consumption analysis for selected asymmetrical ring sets sliding surfaces}

In the performed simulations it has been assumed that the asymmetric shape of the upper sealing ring sliding surface in a given position, moving in the compression and exhaust strokes, moves along the oil layer that it left on the cylinder wall surface in the intake and expansion strokes. The approximate amount of oil that is partially evaporated or burned during the hot gases is taken into account in the mathematical model defining the oil consumption. It is assumed that the additional amount of oil consumption depends on the distance of the tip leading the asymmetric shape of the upper sealing ring towards the combustion chamber and from the instantaneous oil temperature value near the TDC before the expansion stroke, with the height of the piston sliding surface from the piston head to the end of the upper realing ring. The instantaneous actual oil temperature in this range of engine performance also depends on the thermal conductivity of the material applied to the upper sealing ring, piston head, piston and cylinder surface, pressure and temperature generated before and after the expansion stroke in the combustion chamber, and fuel concentration in the oil after a given period of its operation in the engine.

For the given engine kinematic assemblies geometry and the assumed values of the temperatures in the combustion chamber, the data defining the thermal conductivity of the spheroidal cast iron and the selected aluminum alloy used in the manufacture of the pistons, the geometrical data of the main engine assembly, for the duration of combustion flame acting on the cylinder walls surface from its ignition to decay, just before and during the exhaust stroke, and for the ignition temperature of synthetic oil with a dynamic viscosity of $0.0152 \mathrm{~Pa} \times \mathrm{s}$ in the range of 200 to $250^{\circ} \mathrm{C}$, the total amount of oil consumed due to its combustion in the cylinder will hypothetically increase from $16 \%$ to $19 \%$. The percentage value of the amount of oil consumed depends on the gas force, and will certainly increase with the rise in the isochoric pressure increase factor, that is to say, for supercharged engines.

The analysis of the data in Table 3 indicates that, for ring sets 1 and 3, the total oil consumption is much lower than for the reference ring set. This is due to the asymmetric shape of the upper sealing ring with the sliding surface parabolic peak located on the crankcase side. The more oblique angle of the parabola defining the given elliptical shape on the sliding surface on the combustion chamber side results in less oil scraping to the combustion chamber in the expansion and exhaust strokes. This is due to the use of asymmetric shaped contour surfaces of the upper sealing ring with large values of the slip coefficient and small values of the extrusion coefficient. Oil consumption is one of the most important parameters determining the practical application validity of the two sealing rings asymmetrical shapes located in the piston grooves. Each attempt to reduce the friction loss of a piston ring set affects the oil consumption and oil film thickness, and the thickness of the oil film influences the durability of the main engine assemblies.

\section{Conclusions}

Using the data obtained from the simulations, the following conclusions can be made:

- Analyzing the most important effective shaping aspects of the upper sealing ring sliding surfaces by changing the extrusion and slip coefficients values, it is necessary to determine the area of its operation in which mixed friction may occur. This means that the distance traveled by the upper sealing ring must be defined until the oil film left behind by the lower sealing ring is encountered during its return movement for the given engine design.

- The mathematical description of asymmetrical elliptic shapes forces the acceptance of certain values of the distance between the antipodal points of the ellipse, i.e. the pairs of points whose midway point defines the center of the ellipse's symmetry relative to the transverse diameter and the conjugate diameter. The accepted elliptic

Table 3. Specific and hourly oil consumption and the quantity of oil scraped into the crankcase and combustion chamber for each engine stroke for selected piston ring sets

\begin{tabular}{|c|c|c|c|c|c|c|c|}
\hline $\begin{array}{l}\text { Piston ring } \\
\text { setup } \\
\text { variant }\end{array}$ & $\begin{array}{l}\text { Engine } \\
\text { speed n } \\
{[\mathrm{rpm}]}\end{array}$ & $\begin{array}{l}\text { Specific oil } \\
\text { consumption } \\
\mathrm{g}_{\mathrm{o}}[\mathrm{g} / \mathrm{kWh}]\end{array}$ & $\begin{array}{c}\text { Hourly oil } \\
\text { consumption } \\
\mathrm{G}_{\mathrm{h}}[\mathrm{g} / \mathrm{h}]\end{array}$ & $\begin{array}{l}\text { The volume of oil } \\
\text { scraped into the } \\
\text { combustion chamber } \\
\text { in the intake stroke } \\
V_{1}\left[\mathrm{~mm}^{3}\right]\end{array}$ & $\begin{array}{l}\text { The volume of oil } \\
\text { scraped into the } \\
\text { combustion chamber } \\
\text { in the compression } \\
\text { stroke } \mathrm{V}_{2}\left[\mathrm{~mm}^{3}\right]\end{array}$ & $\begin{array}{l}\text { The volume of oil } \\
\text { scraped into the } \\
\text { combustion cham- } \\
\text { ber in the expansion } \\
\text { stroke } \mathrm{V}_{3}\left[\mathrm{~mm}^{3}\right]\end{array}$ & $\begin{array}{l}\text { The volume of oil } \\
\text { scraped into the } \\
\text { combustion cham- } \\
\text { ber in the exhaust } \\
\text { stroke } \mathrm{V}_{4}\left[\mathrm{~mm}^{3}\right]\end{array}$ \\
\hline \multirow{3}{*}{$\begin{array}{l}\text { Reference } \\
\text { ring set }\end{array}$} & 1000 & 9.5 & 1.2 & 0.008 & 0.027 & 0.060 & 0.010 \\
\hline & 3000 & 13.54 & 3.1 & 0.006 & 0.022 & 0.031 & 0.017 \\
\hline & 5000 & 20.79 & 5.7 & 0.006 & 0.026 & 0.058 & 0.016 \\
\hline \multirow[t]{3}{*}{ Ring set 1} & 1000 & 15.89 & 1.6 & 0.022 & 0.034 & 0.074 & 0.024 \\
\hline & 3000 & 13.72 & 3.2 & 0.015 & 0.020 & 0.056 & 0.020 \\
\hline & 5000 & 17.60 & 4.9 & 0.013 & 0.018 & 0.044 & 0.018 \\
\hline \multirow[t]{3}{*}{ Ring set 2} & 1000 & 26.96 & 2.7 & 0.007 & 0.067 & 0.022 & 0.033 \\
\hline & 3000 & 23.10 & 5.4 & 0.004 & 0.041 & 0.021 & 0.026 \\
\hline & 5000 & 51.92 & 14.3 & 0.004 & 0.083 & 0.028 & 0.023 \\
\hline \multirow[t]{3}{*}{ Ring set 3} & 1000 & 16.07 & 1.6 & 0.024 & 0.035 & 0.138 & 0.024 \\
\hline & 3000 & 13.58 & 3.2 & 0.015 & 0.019 & 0.079 & 0.020 \\
\hline & 5000 & 17.67 & 4.9 & 0.015 & 0.018 & 0.064 & 0.018 \\
\hline
\end{tabular}


shapes allow to define the common center of the ellipse position and the distance of the antipodal points that express the transverse and conjugate diameters.

- The shape contours of the upper sealing ring's sliding surface should be characterized by a high slip coefficient value and a low extrusion coefficient value. Contours characterized by a high value of slip coefficient should be located on the crankcase side sliding surface. In case of piston movement in the direction of TDC in the compression and exhaust stroke, contours with small values of the extrusion coefficient must be placed on the opposite side. The contours of the sliding surface of the lower sealing ring should be in the opposite positions relative to the contours of the sliding surface of the upper sealing ring.

- Using the right sliding surfaces asymmetrical contours of both the sealing rings reduces the friction power of the entire piston ring assembly of the $\mathrm{N}_{\text {rsum }}$ by: $14.81 \%$ at $1000 \mathrm{rpm}, 11.32 \%$ at $3000 \mathrm{rpm}$ and $12.57 \%$ at 5000 $\mathrm{rpm}$. It also affects the reduction of friction in $20^{\circ}$ of the crankshaft after TDC for the upper sealing ring by: $16.28 \%$ at $1000 \mathrm{rpm}, 20.24 \%$ at $3000 \mathrm{rpm}$ and $19.82 \%$ at $5000 \mathrm{rpm}$.

- Reduction of the oil film thickness encountered by the upper sealing ring when piston moves towards the TDC in the compression stroke and to the BDC in the expansion stroke results in a distance increase of the crank- shaft angle points defining the minimum oil film thickness. If the thickness of the oil film encountered in both piston movement directions is large enough, both points defining the minimum film thickness for the upper sealing ring slide surface are approaching the angle on the crankshaft near the TDC.

- Using an appropriately selected asymmetrical sliding surface shape of the upper sealing ring can lead to a slight increase in specific and hourly consumption of the engine oil between 1000 to $3000 \mathrm{rpm}$, while maintaining an approximate value of this parameter at speeds of 2500 to $3500 \mathrm{rpm}$ and a significant decrease in the value of this parameter above $3500 \mathrm{rpm}$ - even over $15 \%$ while maintaining good lubrication conditions for all piston rings throughout the entire engine speed range.

- The theoretical assumption of the oil partial elasticity should be considered simultaneously with the mixed friction conditions - in the asymmetric analysis of the sliding sealing rings shape contours - due to the reduced oil film thickness and the angular value of this parameter position in the compression and expansion strokes. Hypothetically, one can use an anisotropic friction model or an elastic-plastic model of orthotropic friction to include these assumptions.

\section{Bibliography}

[1] AKALIN, O., NEWAZ, G.M. Piston ring-cylinder bore friction modelling in mixed lubrication regime: Part I - Analytical results. J Tribol 2001, 123(1), 211-218.

[2] ISKRA, A. Rozkład filmu olejowego na gładzi cylindrowej silnika spalinowego, Rozprawy nr 181, Politechnika Poznańska 1987.

[3] ISKRA, A. Efekty sprężystości olejów syntetycznych a straty tarcia w silniku spalinowym, Journal of KONES'97, Warszawa-Nałęczów 1997.

[4] JAKUBIAK, L., GEMBARA, J. Ocena sprężystych własności olejów smarnych i ich wpływ na parametry współpracy tłoka z cylindrem w silniku spalinowym. KONSSPAL. Wrocław 2000.

[5] SERDECKI, W. Analysis of ring pressure distribution on a deformed cylinder face. Journal of POLISH CIMAC. Energetic aspects, 2012, 7(1), Gdańsk.

[6] STYLES, G., RAHMANI, R., RAHNEJAT, H. et al. Incycle and life-time friction transcience in piston ring-liner conjunction under mixed regime of lubrication. Int $J$ Engine Res. 2014, 15(7), 862-876.

[7] TAULOR, R.I. Squeeze film lubrication in piston rings and reciprocating contacts, Institution of Mechanical Engineers, Journal of Engineering Tribology, 2015, UK.

[8] TIAN, T., WONG, V.W., HEYWOOD, J.B. A piston ringpack film thickness and friction model for multigrade oils and rough surfaces. SAE. 1996, 962032.

Piotr Wróblewski, MEng. - Faculty of Machines and Transport at Poznan University of Technology.

e-mail:piotr.je.wroblewski@doctorate.put.poznan.pl
[9] TIAN, T. Dynamic behaviors of piston rings and their practical impact - part ii: oil transport, friction, and wear of ring/liner interface and the effects of piston and ring dynamics. Proc. Inst. Mech. Eng., Part J: Journal of Engineering Tribology. 2002, 216.

[10] WOLFF, A. Numerical analysis of piston ring pack operation of a marine two-stroke engine. Combustion Engines. 2011, 3.

[11] WOLFF, A., PIECHNA, J. Numerical simulation of piston ring pack operation in the case of mixed lubrication. The Archive of Mech. Engineering, 2005, LII(33).

[12] MAKSAK, W.I. Microsliding and Contact Stiffness of Metallic Bodies, Nauka, Moskau 1975.

[13] FREDRIKSSON, B. Experimental determination frictional properties in araldite b contacts, Rep. LiTH-IKP-R-061, Linköping Institute of Technology, 1975.

[14] ETSION, I. Revisiting the Catteano-Mindlin concept of interfacial slip in tangentially loaded compliant bodies, Trans. ASME, Journal of Tribology. 2010, 132, 020801-1020801-9, 2010.

[15] LIOU, J.L., LIN, J.F. A modified fractal microcontact model developed for asperity heights with variable morphology parameters. Wear. 2010, 268, 133-144.

[16] WRÓBLEWSKI, P., ISKRA, A. Geometry of shape of profiles of the sliding surface of ring seals in the aspect of friction losses and oil film parameters. Combustion Engines. 2016, 167(4), 24-38. 